\title{
O Técnico, o Político e o Morador. \\ Bastidores e Cena Pública do Programa Nova Baixada.
}

Hélio R. S. Silva ${ }^{1}$

\section{Resumo:}

Este artigo foi elaborado a partir de uma pesquisa sobre as relações entre a Baixada Fluminense e o Rio de Janeiro. Tais relações foram estudadas a partir dos nexos fornecidos pelos deslocamentos espaciais (transportes), representações recíprocas dos moradores da zona sul do Rio de Janeiro e de Nova Iguaçu e pelas políticas públicas para a Baixada, aqui representadas pelo Programa Nova Baixada (PNB). O trabalho foi realizado ao longo dos anos 2001, 2002 e 2003. Este artigo oferece uma cena etnográfica dos bastidores de um órgão gestor do PNB. Busca lançar luzes sobre as relações, interesses e circunstâncias em meio aos quais são tomadas as decisões e exercidas as práticas de interesse da periferia. Em meio às mudanças ocorridas nos últimos sete anos, constitui ainda um documento que serve à fixação de uma memória sobre relações da Baixada com o Poder Público.

Palavras Chave: Baixada Fluminense; políticas públicas; transporte público; etnografia; Programa Nova Baixada

\begin{abstract}
:
This article is a partial result from a survey on the relations between Baixada Fluminense and Rio de Janeiro. Those relations were studied from the point of view of spatial displacement (transport), the reciprocal representations of the residents of the southern
\end{abstract}

\footnotetext{
${ }^{1}$ Antropólogo. Professor aposentado da Universidade Federal de Santa Catarina. Pesquisador Associado ao LeMetro - Laboratório de Etnografia Metropolitana/LeMetro/IFCS-UFRJ.
} 
zone of Rio de Janeiro and Nova Iguaçu and the public policies for the Baixada, here represented by the Programa Nova Baixada (PNB). The work was done during the years of 2001, 2002 and 2003. Offering an ethnographic view of the backstage of PNB, the article intends to shed light on the relationships, interests and circumstances amid which decisions are made and practices are decided regarding the periphery. It also contributes to create a memory of the relations of the Government with Baixada, amid the changes in the last seven years.

Key Words: Baixada Fluminense; public policies; public transportation; ethnography; Programa Nova Baixada

\section{Introdução}

Quem integra uma ação governamental decomposta em edificações de creches, urbanização de praças, criação de quadras de esportes, construção de áreas de lazer, implantação de redes de esgotos e de água potável, capacitação do pessoal administrativo e técnico de suas prefeituras, instalação de delegacias de atendimento a mulheres vitimadas pela violência? O destinatário dessas obras, que para ele convergem, e que as assimila em uma vivência integradora da multiplicidade desses bens, serviços e informações. Resta saber como se estabelecem previamente os nexos que asseguram a integração e como se escolhem as séries pertinentes ao objetivo integrador. Ou seja, como se estabelecem correspondências entre os projetos criados e as necessidades que buscam atender?

Identificadas as séries, localizados os nexos, torna-se ainda necessário saber por onde começar e como sustentar a ação. O que também significa manter as mesmas correspondências instauradas entre o projeto e as necessidades no plano de suas realizações concretas e tangíveis. As três séries, as do projeto, realização e necessidades embaralham-se na agenda de contatos entre poder público e população local. Técnicos a serviço de governos ou de instituições transnacionais financiadoras formulam diagnósticos como parte integrante de suas rotinas. Trata-se de uma de suas especialidades, nacional e internacionalmente, consagrada na universidade e acatada nos meios profissionais. 
Populações locais também fazem seus diagnósticos. O problema é que os primeiros parecem subordinados a uma tecnológica, enquanto os segundos radicam-se numa antropológica suscitada pelo contexto. Não se trata aqui de saber com quem fica a razão. Basta reconhecer que diagnósticos, necessidades e expectativas locais, em certos casos muito excepcionais, talvez até mereçam ser “erradicados”, mas em nenhum caso são erradicáveis a partir das mesmas predisposições com que se edifica prédio, urbaniza área e implanta rede de esgoto. Enquanto trabalham, os técnicos estão sempre muito ciosos de uma lógica e de uma coerência que parecem trilhar a linha de montagem, aparando toda excrescência que se interponha em seu diagnóstico, projeto, realização e objetivo. A isto se chama aqui de uma tecnológica. Lógica de técnicos.

Pode não haver lógica nem coerência entre diagnósticos, necessidades, expectativas e objetivos expressos localmente. Mas, certamente haverá um sentido qualquer. Sobretudo quando teimam coletivamente. O problema é que o sentido, que costura objetivos, expectativas, necessidades e diagnósticos locais, só é percebido localmente. O fio que os costura é o da vivência ali. Como se cada local experimentasse maneira peculiar de conciliar necessidades e expectativas e, portanto, de elaborar diagnósticos e traçar objetivos. Talvez haja certa diferença entre equacionar necessidades humanas na prancheta universal e vivenciar as necessidades de uma coletividade no cotidiano local. Pode-se ponderar que não se abrigam no interior de uma metrópole magnas diferenças em torno de necessidades e bens públicos. Qualquer reunião entre técnicos do Palácio Guanabara e moradores da Baixada Fluminenese em torno de necessidades locais jamais instaurará um regime de conversa difícil. Em tal circunstância, o óbvio enfeitará a mesa. Todo o problema se atravessará entre eles precisamente quando as prioridades começarem a ser fixadas e, mais tarde, quando os procedimentos necessários para implementá-las interferirem em suas rotinas.

O que se quer dizer? Que o problema não se encontra em como uns e outros identificam as necessidades, genericamente, e sim na relação que estabelecem entre necessidades e ações, por parte dos técnicos, e entre necessidades e expectativas, por parte dos beneficiários de obras e benfeitorias. E o motivo do desentendimento é o mesmo. Na conversa e na ação governamental que a sucede, os dois lados raramente convergem porque não são guiados pela mesma equação. A relação entre necessidades e aspirações não é da mesma natureza que a relação entre necessidades e ações. A primeira é da ordem 
da vida cotidiana e a segunda é de ordem técnica. A primeira contém uma dimensão existencial de vívida manifestação. A segunda, uma dimensão técnica de ordem racional. Quando se lança mão do recurso “à reunião com a população” para ouvi-la em seus pleitos e para torná-la consciente do processo em marcha, com a maior boa-fé do mundo, e se tem que sair correndo pela janela para não ser linchado ${ }^{2}$, o sentimento de frustração que acompanha a fuga do benfeitor se acentuará pelos dias seguintes. Primeiro, porque sua consciência está tranqüila. Segundo porque não consegue perceber que seu trabalho ali não é uma luva pré-moldada para a mão carente. É possível que tais incorrespondências se acentuem ainda mais nas áreas mais carentes, ao contrário do que supõem muitos técnicos quando se iludem ante o descalabro, supondo que o que puder ser feito é melhor que nada. A equipe que traz um projeto para uma comunidade aviva ao chegar velhas frustrações coletivas. Se muito entusiasmada, sobretudo quando dispõe de recursos generosos, toca em áreas sensíveis e obscuras. Descortina horizontes imprevisíveis para ela mesma, pois não foram forjados no diálogo. O ponto de fuga de tal horizonte não é comum aos dois tipos de interlocutores.

A menção constante a desentendimentos entre técnicos e população da Baixada ilustra com riqueza o cenário apenas diagramado nos parágrafos anteriores. Para complicar ainda mais, instâncias de governo costumam ter necessidades próprias, tornadas públicas com empenho e destreza bem mais claros que argumentos técnicos sobre seus diagnósticos e pleitos públicos sobre suas necessidades. Conflitos entre técnicos inflexíveis quanto a seus princípios e autoridades ciosas de seus interesses têm sido, em nossa história recente, bastante freqüentes e de conhecimento público. O técnico perde sempre nesses embates nos quais seu poder de esclarecer é mínimo, já que obscurecido pela permanente exposição do contendor que atrai para si permanentemente as luzes da mídia.

Outras táticas e manipulações discursivas prosperam na tarefa de desfigurar reivindicações populares e impor a versão "neutra” do político, sabiamente esgrimida como a arte do possível. Onde e quando ocorram choques entre decisões políticas e pleitos públicos, logo os políticos, detentores dos segredos de Estado, argumentam que governar é a arte do possível. O que chamam de possível é coisa entrevista por iniciados no interior da caixa preta que parecem carregar como um troféu. Se do outro lado, o pleito

\footnotetext{
${ }^{2}$ Episódio colhido em entrevista.
} 
se exaspera, o político do lado de cá torna-se cabalístico e lança mão de estatísticas, lembra os limites do orçamento e aponta para os riscos que pleitos assim despudorados criam para a governabilidade. Esta palavra intimida pelo que encerra: praga proferida em nome do realismo. Qualquer coisa que parece difícil conciliar com cidadania. Mas, na verdade não contém nada de novo. Atualiza apenas o velho refrão, "não faz marola pra canoa não virar”. Deixam de ver, muitas vezes, o quanto contribuíram para o descalabro reivindicatório em suas próprias promessas de campanha. Fica parecendo que a arte política consiste em conciliar a generosidade do candidato com a parcimônia do eleito. O problema é operar a transição com coerência. A percepção da sutil mudança do PapaiNoel eleitoral em piloto de nave que exige cinto apertado é muito aguda em regiões e áreas historicamente carentes. É o caso da Baixada Fluminese.

Muitos já não acreditam em governos dedicados a servirem enquanto delegados da população. O que vige ali é a expectativa de poder barganhar alguma coisa possível das contradições entre suas necessidades e interesses de autoridades e candidatos. A população sabe que o voto é importante e pode se tornar útil. Parece calcular o que pode ganhar no varejo sem dar muito crédito às promessas de atacado. Esse não é o discurso de segmentos politizados ou intelectualizados. É discurso de trabalhadores, de donas de casa, de empregados e empregadas do comércio, da indústria ou de serviços que trabalham no Rio ou na Baixada.

\section{População, técnicos e políticos.}

Este artigo se ocupa de um dos três elos de uma pesquisa por mim realizada escolhidos para caracterizar as relações entre a Baixada Fluminense e a Capital do Estado, embora a extensão das linhas que se roçam na tangente seja bem mais vasta. Está, do lado de cá, segmentada em várias Secretarias de Estado e outros órgãos estatais cujas ações incluem a região como objeto e razão de funcionamento. Escolhi um segmento preciso, o Programa Nova Baixada, tocado pela Secretaria de Estado de Planejamento e Coordenação Institucional. É provável que se sobreponha a essa limitação uma outra, a dar destaque à parte do programa que ficou afeta ao CIDE, denominação pela qual, a partir de agora, farei referência à Fundação CIDE, Centro de Informações e Dados do Rio de Janeiro, 
subordinada à Secretaria de Planejamento e que funciona no prédio anexo do Palácio Guanabara.

Em nosso caso, suscitado pelo "Programa Baixada Viva”, logo renomeado "Nova Baixada”, há uma circunstância ponderável. Sua concepção se inicia em momento histórico especial, a abertura politica, pela qual os movimentos populares acedem ao cenário político. Essa circunstância desequilibra um tanto o quadro tradicional das relações entre tecnocratas na prancheta e populações na barricada. A Baixada tornou-se exemplar em todo o Brasil, pela força e pujança de seus movimentos populares, particularmente os de moradores, que elaboraram pautas, organizaram-se para o exercício da pressão política e contaram com aliados notáveis no período, como foi o caso das organizações não governamentais.

No caso do Programa Nova Baixada, acompanhar a origem de tal ou qual idéia, particularmente a de projeto integrado, é tarefa espinhosa que depende de versões e interesses, extremamente erodidas pela parcialidade ou pelas claudicações da memória. Este artigo busca salientar o quanto as instituições governamentais surgem e desaparecem ao sabor de governos, por motivos claros ou obscuros, fazendo de suas equipes nômades sem poder decisório, mas que carregam em suas andanças a maleta de projetos, idéias e intuições. A falta de poder decisório entre eles é contrabalançada pela "falta de imaginação” dos políticos que os dirigem. Na rotina da sucessão de governos, há sempre um momento de perplexidade inaugural: o que fazer? É quando alguém lembra de um escaldado funcionário, este pode vir a ter seus 15 minutos de glória compartilhada com amigos e familiares, pois a tal idéia redentora que adormecia na maleta e hospedara-se em tantos armários de aço quantas foram suas transferências para lá e para cá, tornam-se públicas sob a chancela do guardião do Palácio Guanabara do momento.

A Antropologia Social muito recentemente deu foros de estandarte ao diálogo que sempre praticara, que nem o personagem de Molière: sem perceber que era apenas aquilo que fizera sempre. A descoberta tardia não comprometeu muito a disciplina. No caso porém de coisa pública, que é a nossa coisa e nosso caso, demorar em reconhecê-lo pode dar alguns anos no purgatório, porque se não se configura como lesa-majestade, tolda destinos coletivos e frustra o bem estar público. Há muitas metáforas sobre o poder, desde o rei nu, passando pelo sem terra, até o rei que proíbe milagre de santos ou que garante que o estado é ele mesmo. Falta na galeria o rei surdo, metáfora que cabe como uma luva 
aos governantes fluminenses, pelo menos - justiça seja feita - quando trafega pela Baixada.

\section{Entre a Baixada Viva e a Nova Baixada.}

Foi no Governo Marcelo Alencar (1995-1999) que se criou e se iniciou, em maio de 1995, a preparação do programa de urbanização integrada de bairros da Baixada Fluminense, denominado Programa Baixada Viva (PBV). No período 1995/97 foram elaborados os planos diretores de urbanização integrada dos bairros ${ }^{3}$ e os estudos ambientais, sociais e econômicos, pré-condições para a preparação do Contrato de Financiamento do Programa, cujas condições foram acordadas em setembro de 1997 com o Banco Interamericano de Desenvolvimento - BID. Em seguida, foram preparados os projetos básicos das obras de infra-estrutura dos bairros do primeiro e segundo grupos, para iniciar sua execução com recursos do Estado, enquanto se esperava a aprovação do empréstimo pelo Senado Federal e se cumpriam as exigências formais para assinatura do Contrato com o BID. As obras do primeiro grupo de bairros começaram em abril de 1998 e o Contrato de Financiamento entre o Estado e o BID viria a ser firmado em 28 de julho de 1999. O Governo Anthony Garotinho o rebatizou, em 1999, com o nome que é, na verdade, uma meta, Programa Nova Baixada (PNB). Não se trataria apenas de uma mudança de rótulo. Buscar-se-ia uma nova identidade e, a partir deste último Governo, o programa teria merecido algumas alterações significativas de ordem social. Tudo isso será circunstanciado a seguir.

O Programa seria implantado em três fases, correspondendo cada uma delas a três grupos de bairros em graus diferentes de desenvolvimento. A intervenção implica em licitação das obras e dos projetos executivos, obras de projetos básicos de urbanização integrada. Mais especificamente, rede de esgoto sanitário, ligações domiciliares de esgoto, drenagem de esgoto, recalques e tronco coletor principal de esgoto, pavimentação das partes altas, rede de drenagem pluvial, captação de rios, sub-adutoras, complementação de reservatórios, rede de abastecimento de água, complementação das redes de abastecimento de água, ligações domiciliares de água, pavimentação, construção e

\footnotetext{
${ }^{3}$ Caracterização e Diretrizes de Projeto de Urbanização Integrada.
} 
complementação de obras de equipamentos sociais, construção de postos de apoio à limpeza urbana, reformas de praças, construção de postos de saúde, reforma ou construção de elevatórias. Os critérios para escolha dos bairros objeto de intervenção, levaram em consideração a maior proporção de chefes com renda na faixa entre 3 e 5 salários. Os bairros incialmente escolhidos para a $1^{\text {a }}$ fase (Grupo1) foram Lote XV (Belford Roxo), Olavo Bilac (Duque de Caxias), Jardim Metrópole (São João de Meriti) e Chatuba (Mesquita). Para a $2^{a}$ fase (Grupo 2) foram escolhidos os bairros Xavantes (Belfort Roxo), Jardim Leal/ Centenário (Duque de Caxias), Coelho da Rocha (São João de Meriti) e Santa Terezinha (Mesquita). Para a terceira fase foram escolhidos os bairros Heliópolis/ Itaipu (Belford Roxo), Parque Fluminense (Duque de Caxias) e Éden (São João de Meriti). O Regulamento Operacional contemplava mais dois bairros, Gramacho/Sarapuí em Duque de Caxias e Vilar dos Teles em São João de Meriti. Escolhi Chatuba, uma das experiências mais exitosas do Programa, para que o leitor tenha uma idéia do perfil desses bairros. Pareceu-me mais significativa a descrição mais detida de um deles, do que informações breves sobre todos.

Delimitado, por dois de seus lados, pelo Maciço Gericinó-Mendanha e pelo Campo de Instrução do Gericinó, localizando-se no limite Sul de Mesquita, Chatuba não se situa em região central, mas é acessível, pois atingido por grandes vias e muito próximo do centro de Nilópolis. Possuía, no início do programa uma população estimada em 30.688 habitantes. Apresentava crescimento de 5,05\%, abaixo da taxa de crescimento de 19,1\% de Nova Iguaçu, onde o bairro se situava antes da emancipação de Mesquita Apresentava uma taxa de desemprego de 19,16\% em novembro de 2000, quando a Região Metropolitana acusava 4,8\%. Os dados para 1995, quando o processo de deslocamento para a cidade do Rio de Janeiro já estava em queda, acusam mobilidade de $51 \%$ da população para este destino. Hoje, o percentual caiu para 40,13\%, exprimindo mudanças econômicas na região, sobretudo quando se consideram os 20,74\% de novas ocupações na região, indicador de crescimento. O bairro tinha população jovem, 30\% da qual estava na faixa etária até 15 anos, o que implica em alta demanda escolar. No entanto, sua primeira escola municipal, a Nilson Peçanha Fernandes, só foi criada depois da constituição do município de Mesquita. Conta hoje, portanto, com três unidades escolares, sendo as outras duas estaduais: o CIEP Nelson Cavaquinho, com 480 crianças em 2000; e o Colégio Estadual Pierre Plancher, com 1400 vagas a partir de 2001. Verminoses, 
dermatoses, gastroenterites e hepatites eram as doenças mais comuns no bairro, além dos índices bastante elevados de dengue e ocorrência considerável de leishmaniose.

Segundo avaliação do Programa, “os investimentos realizados no bairro contribuíram para um certo incremento da economia local, sendo possível observar alguma melhoria da rede prestadora de serviços. Verifica-se a expansão de negócios de pequeno porte, que melhoraram a qualidade do equipamento e diversificaram seus produtos. No setor de comércio, algumas mercearias transformaram-se em pequeno supermercado, alguns bares em lanchonetes.”“ Aumentou o número de padarias, de lojas e armarinhos. Merece destaque a instalação de uma grande loja de material de construção, índice, segundo os técnicos, de crescimento do bairro, pela construção de novas moradias, e do reflexo das obras públicas sobre as domésticas, pela reforma das moradias já existentes.

Questão crucial envolve o futuro do bairro. A plena realização do Programa previa desde sua formulação recursos municipais para a complementação de obras e serviços, que correspondem a 20\% da capacidade de investimento da Prefeitura de Mesquita. Embora tais dados não sejam absolutamente conclusivos e mereçam novos exames, observou-se sob o impacto das obras, em alguns dos bairros citados, um afluxo de populações provindas de bairros mais carentes. Criou-se então, pelo menos entre alguns técnicos, a expectativa de um inchaço nos bairros deixados “atraentes” pela intervenção. Expectativa ambígua, pois pareciam temer uma saturação que inviabilizasse o equilíbrio alcançado, exatamente o melhor indicador do êxito do empreendimento. Ambigüidade que deriva diretamente do próprio escopo do Programa que se decidiu pela criação do que, na Baixada, se denominava “ilhas de excelência”. A opção merece sem dúvida o rótulo de desenvolvimento por amostragem, como a criar vitrines que expõem o que não existe em estoque.

\footnotetext{
${ }^{4}$ Governo do Estado/Secretaria de Planejamento/CIDE/ Programa Nova Baixada. ATUALIZAÇÃO DOS DIAGNÓSTICOS DAS CONDIÇÕES SÓCIO-AMBIENTAIS E DOS ASPECTOS INSTITUCIONAIS E DE SUSTENTABILIDADE DO PROGRAMA - BAIRRO CHATUBA 95/2000
} 
Os dados dos bairros, quando comparados com os da Baixada constantes no texto final da pesquisa, revelam claramente o caráter isolado das intervenções e levam a especular em torno da percepção e reação dos moradores de bairros contíguos face ao merecimento dos eleitos e ao critério de eleição. Não era questão que eu pudesse acompanhar sistematicamente, mas que, ao longo da pesquisa, teimava em me assaltar vez em quando, não somente enquanto cogitação de pesquisador, mas também como manifestação de vozes locais. Levantei, portanto, a questão quando entrevistei o Subsecretário da Secretaria da Baixada $^{5}$, morador local e cujas atribuições exigiam constantes deslocamentos na região. Sua resposta foi um dar de ombros. Sem entrar no mérito do Programa, o percebia diluído, dado seu alcance restrito sobre a geografia e o imaginário da população. Parecia traçar um quadro mais grave que o que me assaltara. Aquelas vozes perplexas e descontentes que eu andara ouvindo constituíam minoria insignificante. Pior que despertar o sentimento de injustiça, pela exclusão geral que criava um regime de privilégio porque excepcional, a excepcionalidade dissolvia-se na invisibilidade.

\section{O CIDE no contexto da administração estadual.}

Um ruído constante na administração do Programa Nova Baixada era gerado nos canais de comunicação com a Secretaria de Planejamento (SEPDET). Seus claros ecos partidários asseguravam, no entanto, a transmissão nítida de seu significado no interior da máquina administrativa. Tornava inaudíveis apenas as necessidades e problemas da Baixada, enquanto proclamava que chegavam recursos em época de escassez de dinheiro. O que se fazia, então? Procurava-se pagar o mais tardiamente possível e, quando se liberavam os recursos, tais liberações vinham acompanhadas do máximo de restrição. Imperava uma verdadeira agressividade orçamentária contra os técnicos A dificuldade era de ordem abrangente e de outra ordem mais miúda. Girava em torno de concepções e perdia-se ainda no dia-a-dia nos entendimentos mais triviais, desde pagamentos dos contratados que deveriam passar por aquela instância, à qual o CIDE está subordinado até a criação de óbices para a plena consecução dos trabalhos que cabiam à Fundação CIDE dentro do Programa. Afinal, fora o próprio BID que indicara o CIDE para tocar os programas que lhe ficaram afetos.

\footnotetext{
${ }^{5}$ Secretaria de Estado de Desenvolvimento da Baixada Fluminense do Governo do Estado do Rio de Janeiro.
} 
Os técnicos nunca tiveram a menor idéia do que lá se passava. E as negociações sempre foram difíceis e desgastantes. Nunca houve reunião ou contato entre a vasta equipe que na Secretaria tocava as obras com a pequena equipe que, no âmbito do CIDE, cuidava dos programas institucionais. Os contatos limitavam-se à cúpula do CIDE, seu Presidente, o Coordenador Técnico e duas técnicas que funcionavam como assessoras especiais. O clima desses contatos e dessas reuniões tinha um caráter esotérico. Pouco transpirava de seu teor. Tratavam-se de "questões de estado", no sentido mais trivial que a expressão suscita ao leigo, e não de questões técnicas nas quais as duas equipes estavam envolvidas e que requereriam, no mínimo, e em nome da responsabilidade com as populações envolvidas, o máximo de transparência.

A princípio, ainda no Governo Anthony Garotinho, em nossas conversas, nós, os técnicos da equipe menor (nos dois sentidos do termo), atribuíamos as dificuldades a eventuais falhas de comunicação ou inabilidade daqueles que no CIDE faziam a ponte entre as duas instituições. Ou, às vezes, cogitávamos numa eventual fragilidade política de seu presidente à época. A primeira mudança de governo deixou claro que não era este o caso. As dificuldades persistiram. Ora, essa mudança provocou verdadeira reviravolta na máquina do Estado, pois já houvera um rompimento entre a vice-governadora que assumia e o governador que se afastava, com a substituição completa das cúpulas de ambos os lados. Sem falar em inúmeros técnicos mais visados, dados seus notórios vínculos com integrantes do governo anterior. ${ }^{6}$

Programa destinado à Baixada Fluminense, região a cuja singularidade se deve a criação de uma Secretaria específica, torna-se curioso que tal Secretaria não tenha sido envolvida pelo Programa e não compartilhe de seus recursos. Em certo período, houve maior aproximação entre a Secretaria e o CIDE, atenuando os efeitos nocivos da duplicidade. O Secretário à época teria recomendado uma aproximação entre o CIDE e a Secretaria da Baixada. Um de nossos entrevistados envolvidos em tais contatos diz categoricamente:

\footnotetext{
${ }^{6}$ Em ambos os casos, em época de recursos escassos, os empréstimos repassados pela Unesco, que eram na verdade significativos, adquirem um sentido transcendente para os integrantes do governo. Lembro-me à época de ter ouvido algumas vezes em Nova Iguaçu menções a este filão que estaria escoando nos porões do CIDE. É verdade que a parte do leão ficava na Secretaria, que embora não ficasse imune à cobiça, talvez tivesse, pelo seu próprio status, capacidade maior de se desvencilhar, não só das críticas como ainda dos inumeráveis candidatos a parceiros que, vindos de outras secretarias, procuravam a Fundação para as mais mirabolantes parcerias.
} 
“nenhuma demanda da Secretaria da Baixada deixou de ser atendida”. Ora o que se coloca aqui em termos dessa parceria, é que à Secretaria da região talvez coubesse, no Programa um papel mais saliente do que o de mero demandante. ${ }^{7}$

A primeira passagem de Governo implicou em uma exigência: a que se demitissem os trinta técnicos contratados pelo CIDE para executar os componentes institucionais do Programa Nova Baixada. Como não se tinha sequer discutido ainda o próprio Programa, a Presidente à época julgou a demanda intempestiva. A exigência vinha do superintendente de orçamento, uma espécie de tesoureiro do PNB. Queriam manter apenas cinco dos trinta contratados. Como se tratava de um governo de apenas nove meses e uma nova passagem de governo viria acompanhada de novas exigências, considerava as demissões irracionais, pois desarticulariam uma equipe já constituída, impondo aos novos contratados a necessidade de um aprendizado e entrosamento cujos frutos não seriam alcançáveis a curto prazo. Houve inclusive uma passeata dentro do Palácio organizada pelos trezentos que foram demitidos na Secretaria de Planejamento. Essas demissões teriam sido feitas sob a alegação de que tais técnicos não teriam "nada a ver” com a Baixada. Para a Presidente, sob a justificativa, ocultam-se motivações políticas que significavam simplesmente demitir os "deles" para colocar os "nossos".

O que revelava que apesar dos quatro governos, com perfis políticos distintos, a administração do Nova Baixada mantém algumas propriedades comuns, quais sejam, uma forte tendência a contratar pelos critérios partidários com o objetivo de maximizar os recursos disponíveis em tempo de escassez. Ao negar-se a atender a sugestão de demissão coletiva feita pela Secretaria e consciente da hostilidade do CIDE em relação à equipe adventícia, essa Presidência decidiu-se pelo envolvimento de todos com a Baixada. Uma

\footnotetext{
${ }^{7}$ Essa neutralização provavelmente tem implicações políticas que permaneceram obscuras para mim. E embora acompanhasse as grandes linhas de sua rotina, não tinha acesso ao teor de suas articulações mais sigilosas. Envolvem com certa regularidade as atividades "secretas" dessas verdadeiras seitas que se instalam nas instituições de Estado e para cujo acesso são necessárias práticas “iniciáticas”. Não pude ter acesso aos segredos das alturas do poder e nem aos do subsolo. Aos primeiros porque trancados a sete chaves, os segundos por limitações técnicas. A questão do saneamento e do abastecimento de água carreava muito dinheiro e obras que, segundo alguns técnicos no tema e administradores do Programa teriam incorrido em alguns erros. Em dado momento, alguns postularam sua correção. Outros preferiram maquiar os deslizes e dar prosseguimento às obras. Torna-se ocioso esclarecer que os primeiros eram técnicos e os segundos políticos. O que talvez mereça esclarecimento é a circunstância curiosa de que a opção pela maquiagem ocorria em transição de governo. Poder-se-ia imaginar uma tendência política "natural” a denunciar os erros do adversário. Prevaleceu, no entanto, a compulsão às inaugurações com as quais se festejam, tradicionalmente, períodos eleitorais
} 
espécie de apelo (“vamos para a Baixada”) passou a dar o tom institucional ali por essa época. Percebia a possibilidade de levar para a Baixada professores e pesquisadores da Universidade e a classe média da burocracia estatal e estima que, hoje, poderiam estar trabalhando na Baixada, em regime, integral umas duzentas pessoas. Acredita, no entanto, que a possibilidade teria sido frustrada pela própria desconfiança das lideranças políticas locais, temerosas de que o processo viesse a retirar deles suas prerrogativas.

\section{O contexto do CIDE.}

Havia ali, em agosto de 2001, quando se deu o primeiro contato, certa intenção de ampliar o leque de atividades do CIDE, ou pelo menos complementar suas atividades de produção de indicadores e estatísticas com estudos qualitativos de ordem social, cultural, política e econômica. Parceria firmada com a Universidade Federal Fluminense já vinha assegurando a publicação d’O Boletim de Economia Fluminense. Demanda de instituição que trabalha com dados e informações, posteriormente questionada pelos técnicos do CIDE, apesar de, na apresentação do Anuário Estatístico de 2001, se reconhecer que não seja possível “captar todos os aspectos do processo social através dos dados estatísticos”.

Tratava-se de vaga intenção. O trabalho etnográfico ficou restrito ao Programa Nova Baixada do qual couberam ao CIDE os projetos de desenvolvimento institucional. Atribuição controversa, que contrariava o diretor técnico e alguns de seus auxiliares. Consideravam-nos estranhos à instituição. Esse diretor declarou em certa reunião que o Cide não teria "pernas para isso”. Não era a opinião de seu Presidente, que assegurou sua permanência na Casa. Parecia vislumbrar possibilidade, embora remota, de que as atividades tradicionais fossem acrescidas de estudos críticos e qualitativos que instrumentassem o Governo para pensar o Estado e a Região Metropolitana. Revelava admiração pelo trabalho da Fundrem ${ }^{8}$ e lamentava seu desaparecimento.

A concordância em torno da limitação ou especificidade dos trabalhos quantitativos ou estatísticos não assegura perfil comum a seus postulantes. Pode-se, na perspectiva

\footnotetext{
${ }^{8}$ A FUNDREM - Fundação para o Desenvolvimento da Região Metropolitana, foi criada na década de 70, no Governo Faria Lima, no Estado do Rio de Janeiro, tendo sido extinta no governo Moreira Franco. Tinha como objetivo principal a elaboração de Planos Diretores para os municípios da área metropolitana.
} 
socialista ${ }^{9}$ dos seus últimos governos, aguardar um trabalho que desse conta dos conflitos de classe na Baixada para perceber como se organiza a população local para enfrentar desafios e problemas. Pode-se, ainda, aguardar o resgate de um estilo de vida e de uma visão de mundo regionalmente constituídos. É expectativa generosa e interessada, mas quase sempre vazada em termos deslocados para o estágio crítico em que se encontram as ciências sociais. Um terceiro tipo de expectativa revela-se na expressão "alma do homem da baixada”. Parece aguardar uma essência produzida naquela experiência histórica e geográfica. Remete aos velhos estudos de caráter nacional ou às tradições regionalistas, cultivadas por um certo Gilberto Freyre, Adonias Filho, Wilson Martins, Alfredo Ellis Jr., vários românticos, tantos modernistas. Um quarto tipo espera a recuperação de "traços culturais” ou um inventário de manifestações sociais, num suave sentido folclorizante, mas - deve-se reconhecer - mais palatável para a máquina pública no sentido de conversão em ações de Estado.

Outra particularidade digna de nota é o lugar onde estão instalados esses cento e vinte técnicos, pequena e operosa comunidade com um ethos bem distinto dos demais órgãos que funcionam no Palácio Guanabara. O que os rege é o princípio do envolvimento. Nos três governos que se sucederam durante o tempo em que ali permaneci, pois mesmo durante os 10 meses de campo na Baixada, participava com certa regularidade de reuniões e seminários no Palácio, pude perceber o clima que o agita. Manifestações de rua, protestos, reivindicações, rua interditada. Assessores, secretários e funcionários que se apressam a atender pleitos, conciliar interesses, oferecer respostas a suas populações. Problemas e crises crônicas que devem ser administrados. Demandas urgentes.

Todo esse clima impõe uma rotina de trabalho febril e absolutamente compatível com o que está em jogo. Mas, não é de maneira nenhuma o clima favorável a uma comunidade que se agrega pelo princípio de distanciamento crítico. Pude perceber nitidamente como o grupo congregado no CIDE opera simbolicamente, orientando comportamentos e posturas para produzir fronteiras. Sistematizar esse conjunto de observações mereceria um capítulo à parte que o escopo deste trabalho não suporta. Vale a pena, contudo, fazer referência a esse aspecto no contexto geral dessa caracterização das disposições e ações em relação à Baixada Fluminense por parte de um dos órgãos gestores do Programa Nova Baixada.

\footnotetext{
${ }^{9}$ A palavra está sendo usada em sentido lato. Espera-se que não confunda mais do que esclarece.
} 
De um modo geral, os funcionários do CIDE são técnicos empenhados e competentes. E como desempenham funções técnicas, algumas de certa complexidade, desenvolvem no ambiente do Palácio um nítido ethos aristocratizante. O segregamento atual e a dedicação com que exercem seus misteres tornam o grupo, em meio à caixa de ressonância que é o Palácio da Guanabara, um tanto gauche, um quanto empertigado. ${ }^{10}$ Esse comportamento genérico produz exceções e não é compartilhado com a mesma intensidade por todos. Resulta do próprio deslocamento institucional e do fato de um pequeno grupo permanecer à míngua da interlocução fecundadora, com iguais, seus pares, de outras áreas, o que ocorre em universidades. Deriva ainda da exclusiva dedicação à pesquisa sem os respiradouros da extensão e da experiência docente. Mas, sobretudo, é produto da vizinhança do poder, do atrito com uma máquina febril que administra um dos mais complexos estados brasileiros num regime extremamente desfavorável aos interesses públicos.

E outro traço do funcionamento da máquina estatal, este menos obscuro e de amplo conhecimento, embora testemunhá-lo em seus detalhamentos reconfigure seu próprio sentido, espécie de lei de sobrevivência, consiste em desconfiar permanentemente de figuras novas, sobretudo quando chegam com idéias novas. A visão média sobre o adventício oscila entre o pânico de que ele arrebente com toda aquela quietude e o sentimento de ridículo de quem, sem experiência alguma institucional, ousa mudar. Pareceriam quixotes, mas quixotes perigosos porque investem não contra moinhos de vento, mas contra rotinas consagradas e perspectivas consolidadas legalmente. Os funcionários públicos mantêm um traço comum com os advogados. Estes costumam dizer que real é o que está nos autos. Aqueles parecem acreditar que a realidade é fruto do regulamento.

Pode-se por hipótese simular outra ordem de interpretação, perfeitamente articulável com as precedentes. O que soa e parece com um certo ethos de evitação no comportamento

\footnotetext{
${ }^{10}$ Uma certa arrogância muda e conspiratória, em nome do saber que detêm, soava-me curiosa, pois nunca a percebi no âmbito de universidades federais ou as boas universidades particulares do país, eu que vinha deste mundo. Treino aqui o que farei em Nova Iguaçu. Até que ponto este tipo de observação é produto do treinamento profissional ou efeito do deslocamento do contexto original para este novo contexto? O que implica em pensar a observação sempre como situada.
} 
cotidiano de tais técnicos talvez seja uma imposição de produção de distância em relação aos interesses políticos e administrativos que, obviamente, encontram no Palácio Guanabara área sensibilíssima. Acrescente-se a tal circunstância que, enquanto instituições de pesquisa produzem sua imagem na continuidade de suas equipes e numa tradição que consolida know-how, constitui um acervo de conhecimento, uma experiência prática com teorias, métodos e técnicas compartilhados e em contínuo aprimoramento, o poder público parece começar de novo a cada quatro anos, sob o signo da ruptura. Secretarias são extintas, outras são criadas ou mudam de nome quando não são possíveis as primeiras possibilidades. Atribuições e órgãos são realocados no organograma. Costumam trazer para a posse listas infindáveis de compromissos assumidos em campanha, entre eles as dívidas para com os abnegados correligionários, cabos eleitorais e aliados de outros partidos, que devem ser ressarcidas com cargos honrosos. Isto sem mencionar a parentela e a parentela de aliados, correligionários e cabos eleitorais. Fiel à distinção estabelecida por Roberto DaMatta entre mundo de casa e mundo da rua, é provável que a parentela conte até com maior poder de barganha. Consta, a boca pequena, que, diante das graves denúncias da imprensa da época a seu exagerado cuidado em obter sinecuras para parentes e contra-parentes, o Presidente interino, José Linhares teria confessado a amigo íntimo: "as críticas da imprensa eu suporto porque são passageiras. As queixas de parentes contrariados me acompanhariam para o resto da vida.”

Neste sentido, meu período de trabalho para o CIDE, embora curto, foi extremamente fértil, pois fiquei sob as ordens de três administrações e pude acompanhar relativamente de perto duas transições de governo. ${ }^{11}$ Sagüi de outros galhos, inicialmente tornei-me entusiasta da visão generosa do Presidente e passei a olhar seus opositores como técnicos limitados e perdidos na tecnocracia das pequenas atividades. Afinal, nem os produzia, visto que os dados trabalhados pelo CIDE são compulsados de diversas fontes e deles desagregados. Com o tempo, fui percebendo que não havia vilão na pendência e que ambas eram concepções legítimas e apenas diferentes. Afinal, instituições com perfis mais ou menos equivalentes haviam trilhado a via que o Presidente propunha. O IBGE

\footnotetext{
${ }^{11}$ Meu período de trabalho transcorreu entre outubro de 2001 até dezembro de 2003, sob os governos Anthony Garotinho (de $1^{\circ}$. de outubro de 2001 até 31 de março de 2002), Benedita da Silva (de $1^{\circ}$. de abril até 31 de dezembro de 2002) e Rosinha Garotinho (de $1^{\circ}$. de janeiro até 31 de dezembro de 2003). Perplexo com o rumor interno, quando da primeira mudança a que assisti, interroguei uma engenheira do Palácio que ali trabalha há 20 anos: “ - O que muda?” E ela, com a tranqüilidade de quem já passara por todas as tempestades, não pestanejou: “ - As divisórias das salas e as tomadas dos rodapés. Ninguém gosta da posição da mesa de seu antecessor.”
} 
que, já em 1941, publica o alentado volume de “A Cultura Brasileira” de Fernando de Azevedo e, ao longo das décadas seguintes, produz e patrocina empreendimentos equivalentes. A Fundação Getulio Vargas, tradicionalmente conhecida do grande público apenas pelos seus índices, sofreu há um pouco mais de vinte anos guinada significativa.

No entanto, outros modelos respeitáveis limitam-se à circunscrição mais restrita da visão dos técnicos da casa. No caso, a resistência a incorporar o Programa Nova Baixada era interpretada com outra ordem de argumentos na segunda administração à qual fiquei subordinado durante minha pesquisa. Naquela ocasião, a percepção da presidência era a de que não se trataria de uma resistência generalizada entre seus técnicos, mas da posição de uns quatro diretores que formariam dentro da instituição um grupo entrosado. Argumentava-se então, contra a opinião desta cúpula de diretores, que a própria criação do CIDE tinha uma importância estratégica no esforço em prol do desenvolvimento do Estado. Parecia a seus argumentadores que declinar do desafio que o Programa impunha era um tanto ferir o próprio fundamento sobre o qual se imaginara e criara a instituição, posto que a Baixada se apresentava como um dos maiores desafios a esse projeto de desenvolvimento.

Segundo tais fontes, a instituição contava com excelentes técnicos em georeferenciamento, despoluição e outras especializações extremamente úteis no esforço de produzir diagnósticos sobre a Baixada e para se associar na formulação de projetos para a região. Como instituição produtora de estatísticas, dados e informações, lhe caberia ainda a responsabilidade de conceber políticas, já que conta com técnicos capazes de organizar projetos em todas as áreas, da despoluição à polícia. O critério que negava sua pertinência no âmbito do Nova Baixada, desautorizaria, segundo tal linha de raciocínio, a existência na instituição de outros programas ali abrigados, como o Programa de Despoluição da Baía de Guanabara ou o Programa de Geo-referenciamento para a Secretaria de Segurança.

O que haveria, segundo esse tipo de análise, era um interesse desses técnicos em gerenciarem os recursos do Programa, tomando decisões quanto a prioridades e alocação de recursos. O argumento parece confirmar a tensão permanente no interior de alguns órgãos de estado entre concepções e critérios técnicos e políticos. Os defensores dos padrões de aferição política, acusando os técnicos de falta de sensibilidade para contextos 
sociais e, de certa forma, de alienação quanto à densidade dos interesses políticos que não podiam ser confundidos, no limite, como necessariamente escusos ou meramente eleitoreiros. ${ }^{12}$ Compartilhado por todos ou imposto como bandeira por alguns diretores técnicos, o fato é que havia uma rejeição ao Programa. Tanto que, em determinado momento, sua Presidente decide, com a equipe contratada, acentuar a presença do CIDE naquela região. Ela mesma, como meio prático e de efeitos simbólicos, decidiu-se por manter um regime de dupla residência, passando parte da semana no Rio e outra parte na Baixada.

A rejeição técnica ao Programa, pelas razões expostas, mantinha sólidas relações com a rejeição à Baixada, por outras razões. Estas, meramente sociais e simbólicas, produto do que se chama aqui "mentalidade zona sul”. Um dos presidentes, dentre os três sob os quais trabalhei, reconheceu em entrevista essa dessintonia com a Baixada. Procurou acercar-se de D. Mauro Morelli, figura central na discussão da fome e com reconhecido prestígio e serviços prestados na região e do Secretário da Baixada cuja “figura me pareceu grandiosa”. ${ }^{13}$ A desilusão que a declaração exprime revela bem a natureza da engrenagem. Quem contraria práticas tradicionais em tais instâncias sofre apenas desgaste que, dependendo do temperamento, pode ser incorporado como inútil, insensato ou ridículo. E, no entanto, focalizadas as coisas a partir de um critério onde o mínimo sensocomum prevaleça, seu apelo para que uma equipe constituída para trabalhar na Baixada, visite a região de vez em quando para ter uma idéia do que se trata, não pode parecer insólita ou fora de propósito. Bem mais insólita foi a decisão de instalar os 30 técnicos que não cabiam no Palácio, na rua Real Grandeza, ao lado do cemitério. Não pelo cemitério em si, mas pelos quase 50 quilômetros que separavam suas dependências do verdadeiro lugar de trabalho.

\footnotetext{
12 "O quadro técnico do CIDE, por outro lado, tinha uma grande rejeição ao PNB, sobretudo uns quatro diretores em torno dos quais esses técnicos gravitavam. Fizeram então uma política contra o Programa. Na verdade, estavam querendo dominar os recursos existentes, já que a argumentação de que o escopo do Programa não seria compatível com a Instituição, teria como conseqüência imediata questionar a presença ali de outros programas como o PDBG e o programa de geo-processamento para a Secretaria de Segurança Pública. [Declaração de Presidente do CIDE à época, em entrevista ao autor].
}

\footnotetext{
${ }^{13} \mathrm{O}$ caso ilustra os equívocos a que os adventícios, embora de boa-fé, estão sujeitos quando em contexto novo. A "figura grandiosa” do Secretário, com reduto eleitoral em São João de Meriti não conseguira sequer, na penúltima eleição, eleger-se vereador em sua cidade. Volta à carga nas últimas eleições, tentando a Prefeitura, e obtém um medíocre $4^{\circ}$. Lugar.
} 
Essa oscilação da informante, entre o otimismo empreendedor que marcou sua administração e o ceticismo melancólico que deu o tom de sua entrevista, paira como uma tensão bem mais ampla que se estende sobre muitos funcionários públicos do estado. Há em várias falas de funcionários com maior experiência uma descrição rica a períodos febris durante os quais o trabalho "empolgava"14, seguida da seca e realista afirmação de desistência, seja para dizer que "não tem jeito mesmo"15, seja - e preservando metade da dignidade - para aguardar que "os mais jovens que continuem a luta" ${ }^{16} \mathrm{~A}$ diferença entre as falas se estabelece no tocante ao motivo da desilusão. Em todos os casos não parece advir de um acúmulo de desgastes. Surge sempre de um episódio específico que o/a magoou, feriu, decepcionou. A diferença mencionada é da ordem da explicitação, muitos falam do episódio, outros mantêm um silêncio ao longo do qual um suspiro, um dar de ombros ou uns lampejos no olhar parecem indicar que o fato está sendo rememorado em surdina. O entrevistador permanece mudo em tais ocasiões. Não há em que insistir. Fica ali, meio inútil, testemunha do constrangimento, tendo como pista apenas o esqueleto da engrenagem que tenta preencher com umas carnes de palpite. Tais palpites podem nunca flagrar exatamente a circunstância que motivou o caso específico que observa. Depois de certo tempo de observação e escuta, no entanto, talvez o que a imaginação lhe traga tenha um alto teor de probabilidade. É que a arena pública opera nesses casos com uma dura primitividade. O elementar irrompe com certa constância, expondo sem rodeios seus interesses crus.

De qualquer forma, as referências ao período encantado da paixão pela coisa pública estão crivadas de informações institucionais, políticas e técnicas que apontam para insuficiências gritantes, limitações muito claras. Nos relatos, o corte da decepção vivido como intempestivo pelo informante soa ao ouvinte como previsível. Talvez por isso os relatos se estruturem sempre em torno de dois registros, ímpeto e corte. A quem ouve, fica parecendo que o entusiasmo desmedido, ao invés de um apaixonado compromisso com a causa pública, parece mais uma atuação compulsiva que impede ao ator em causa de perceber onde está. O que explica a recorrência ao corte no relato, isto é, ao episódio

\footnotetext{
${ }^{14}$ Expressão usada por outra entrevistada.

${ }^{15}$ Idem.

${ }^{16}$ Idem.
} 
espinhoso que o traga para a decepção acomodada. Contrariando portanto o verbalizado, é o acúmulo dos entraves obscurecidos pelo entusiasmo que na verdade frutifica no corte súbito. Como se o fruto podre da decepção, repentinamente exposto, estivesse na verdade apodrecendo há muito tempo. E a experiência desse tempo permite que tudo se revele em um instante, como uma epifania, um insight, uma serendipidade. ${ }^{17}$

A Presidente, que abandonamos há cinco parágrafos atrás, não tinha esse perfil. Não era uma funcionária pública do estado e permanecera na presidência durante o curto período dos noves meses do Governo Benedita da Silva. Sua fala é de analista, pois seu perfil é acadêmico. Faz quando fala, assim como eu, uma etnografia institucional. Envolvida, é claro, porque estava no epicentro de tudo. Sua decisão de trabalhar e advogar pelo óbvio suscitou, entre funcionários, entre partidários do partido que a apoiava duas linhas de interpretação. O primeiro a considerava louca furiosa, o segundo louca mansa. Mentiras, distorções e versões fantasiosas crivaram sua permanência ali e mantiveram-se cristalizadas depois de sua saída na lápide para vivos que os meios públicos sempre erigem para os que são apeados do poder.

\section{Intrusos.}

A resistência institucional, as obrigações tradicionais da casa impuseram a constituição de uma equipe paralela que ficasse responsável pelas tarefas e misteres que o Programa Nova Baixada exigia e demandava. Seus integrantes eram contratados temporários e foram selecionados pelo exame de currículo e entrevistas, posteriormente submetidos á UNESCO. Seus salários em média eram superiores aos vigentes na instituição. Ora, para quem conheça um pouco a tradição e o cotidiano de uma instituição pública estadual, imediatamente concordará que os três ingredientes são mais explosivos do que um composto de coquetel Molotov. Havia, no entanto, entre eles, duas funcionárias dos quadros estáveis do CIDE e que trabalhavam no Programa desde sua criação no Governo Marcelo Alencar. Seus perfis continham os mesmos traços utilizados para descrever os técnicos do CIDE. Extremamente envolvidas com o trabalho, capazes de mantê-lo aceso ao longo de dez, doze, quatorze horas diárias. Uma diferença para com os técnicos era a

\footnotetext{
${ }^{17}$ Aproximadamente, as palavras elencadas significam revelação e, ainda bem aproximadamente, distribuem-se em campos específicos, o psicológico (insight), o religioso (epifania) e o científico (serendipity).
} 
paixão pelo trabalho de campo, envolvendo-se com a Baixada, deslocando-se entre seus municípios e estabelecendo sólidos vínculos com moradores e técnicos e funcionários que tocavam as obras locais.

Uma delas me levou pela primeira vez para conhecer os bairros contemplados com obras e para mostrar a Baixada em geral. A cicerone demonstrava-se sempre envolvida ao descrever etapas do trabalho e reviver empreendimentos aos quais emprestava maior valor. Essa disposição contrastava com a dos outros técnicos da casa que não participavam do Programa Nova Baixada. Primeiro por não considerarem relevante visitála para conhecê-la. Afinal, bastava o cruzamento dos índices de tantas fontes que sabiam manusear com destreza para que o quadro inteiro se revelasse no monitor de seu micro na sala refrigerada. O recurso ao percurso traria apenas um roteiro aleatório e ininteligível. Uma experiência empírica e sem valor heurístico. Ficariam apenas a sensação do calor insuportável, as fachadas desbotadas de residências precárias e o sabor das mortadelas pouco convidativas de seus bares na hora do lanche.

Por falta de espaço, seus integrantes foram acomodados em prédio público do Estado vago à época. Passou a trabalhar, a partir de novembro de 2001, na rua Real Grandeza em Botafogo. Havia a vantagem de ficar relativamente perto do Palácio Guanabara, o que facilitava deslocamentos em caso de reuniões ou seminários e a curiosa desvantagem de se situar a mais de 50 quilômetros da Baixada onde iriam atuar. Essa equipe conviveu em um velho casarão abandonado cuja arquitetura bizarra desisti de entender. Para que teria sido construído? Um vastíssimo salão continha tantas colunas que era de se duvidar da segurança do teto. No primeiro e terceiro andares funcionavam dependências do SEBRAE e nós nos instalamos no grande salão, reservadas duas salas de frente, uma para secretária e coordenador administrativo e a outra para mim, a coordenadora do projeto e duas assessoras. O trabalho era imenso, complexo e exigia disposições para além de toda rotina. A equipe era extremamente heterogênea quanto à formação, exigência do leque variado das ações a serem desenvolvidas. Trata-se, portanto, de experiência digna de estudo por especialistas em administração ou em “cultura organizacional”.

Situações intensas e sempre novas, enfrentadas por equipe sem tradição de trabalho em comum e com horizonte limitado, pois as contratações foram firmadas por tempo determinado. Acrescente-se a isso, a circunstância de que atravessamos durante o período 
três governos, e quem trabalha na máquina pública sabe muito bem as desarrumações que mudanças de governo provocam, com suas mudanças de secretario, de concepções e prioridades. Mas, alteram, sobretudo, a imaginação dos funcionários que parecem ler todos os sinais que chegam “de cima”. Economista, engenheiro, professor de História, especialista em geo-processamento, especialistas em estudos urbanos, professoras e pesquisadoras da PUC e da UFF e até um antropólogo.

A idéia de confiança nesses casos opera curiosamente. Conduz a escolhas em âmbitos restritos de relacionamento porque são nestes que a confiabilidade de um pretendente ao cargo já se encontra suficientemente testada. O nepotismo nessa aproximação mais íntima não significa necessariamente uma cavilosa operação de ajuda a parentes e amigos. Termina tendo esse sentido. Mas no dia-a-dia revela-se como um critério sinceramente assumido como legítimo. É como se o conhecido, parente ou amigo evidenciasse qualidades morais e competência técnica que são aferíveis exatamente pela proximidade de conhecimento que a amizade ou o parentesco asseguram. A escolha mediante concurso ou entrevista, plausível mesmo no caso de contratação temporária, parece oferecer limites e limitações à possibilidade de aferir com certeza os atributos necessários ao cargo que, ao contrário, o convívio garantiria.

Um especialista em administração pública, eticamente preocupado com a modernização das instituições oficiais poderia contra-argumentar, com razão, que a distinção é irrelevante. No que terá toda razão, do ponto de vista do funcionamento da máquina administrativa. Mas, essa provável irrelevância talvez esteja dizendo alguma coisa de muito particular do ponto de vista de nossa sociedade. Ressalve-se, contudo, uma circunstância curiosa. A minha própria contratação. Fui indicado por um desafeto público e notório do Governador Anthony Garotinho que, à época, acabara de lançar um livro de grande sucesso nacional que era verdadeira declaração de guerra contra o referido governador, suas práticas e seu ideário. Aquele Presidente não era apenas um dirigente do CIDE, mas um integrante do grupo mais restrito que o assessorava. Não obstante, me admitiu e me manteve no cargo, apesar de algumas pressões que sofrera quando ficaram evidenciadas minhas relações de amizade com o desafeto do Governador. Os cargos altos, nenhum deles, obedeceram à lógica do nepotismo.

\section{Algumas considerações.}


Não foram poucos os que mencionaram o aprimoramento da consciência das populações locais ao longo das idas e vindas do Programa. Uma técnica que o acompanhou desde o início, parece ter uma percepção bem clara do fenômeno. O clima no barracão de obras é ufanista. As obras teriam mudado a face de Chatuba. O que não impede, ou não impediu pelo menos no dia em que exibimos o vídeo produzido domesticamente pela equipe do CIDE/UNESCO - os protestos indignados dos presentes, sobretudo de Dona Lourdes. Sua ira - contra a propaganda de Estado - nos conduziu imediatamente a um ajuntamento de casas - um, dois cômodos cada uma - reunidas pelos mesmos princípios que congregam os ciscos varridos por uma vassoura. Lá estavam depositadas contra o muro de uma igreja, cuja construção irregular represava dejetos dos esgotos comuns. Afundávamos os pés na lama, passos ciscando o solo, o fedor enchendo nossos pulmões. Chamou uma mulher esquálida, mãe de meia dúzia de crianças sitiadas entre os tijolos crus.

A minúscula paisagem encurralada aqui fora, a escuridão lá de dentro, a tarde tropical e a lâmpada acesa sob um fio pendente. Era uma paisagem prisioneira, o esgoto a correr a nossos pés, os tijolos crus emoldurando tudo resumidamente, o paredão do templo separando severo o paraíso do inferno. A mulher chamada entrou em cena como um ator empurrado para o palco sem texto qualquer. Procurava a expressão adequada à situação, mas - nós - convocados pela indignação de Dona Lourdes - éramos estranhos para ela, que parecia compartilhar com a gente o sentimento de absurdo. Ao todo, eram quase duas dezenas de crianças, proibidas de sair daqueles buracos, pois três delas já tinham sido chupadas pela leptospirose. Passado o torpor inicial, a mulher começou a responder às perguntas de Dona Lourdes, enquanto, vacilávamos no interior daquele círculo pestilento.

A amplitude das ações propostas pelo Baixada Viva e, posteriormente, pelo Programa Nova Baixada revela claramente a gravidade dos diagnósticos que a nortearam. Corroboram de certa maneira o provável tom dramático de certas passagens deste texto. Rebate-se claramente com as vozes ouvidas na Baixada. O espectro é amplo e já foi suficientemente sinalizado. A ambição da intervenção e sua amplitude esbarram, no entanto, com a evidência do caráter restrito de seu alcance. A possibilidade mais otimista de um êxito pleno terminará por criar na Baixada ilhas de exemplaridade facilmente tragáveis pela carência circundante. Em grau menor e num projeto bem menos ambicioso, mas que não deixa de ser notável, foi o que se passou em Rancho Fundo, a partir de movimento de moradores e do trabalho do CECIP. 
Rancho Fundo tornou-se modelar e quem se aproxima do bairro pela quase intransitável avenida que lhe dá acesso, via Posse, percebe as diferenças gritantes em termos de limpeza urbana, asfaltamento e arborização, além de inúmeras outras realizações menos visíveis, como a exemplar Biblioteca Paulo Freire e outras realizações como cursos e trabalho voluntário de ajuda a famílias que passam dificuldades. Houve ali uma conscientização e mobilização com reflexos nítidos. No entanto, limitados. Em volta, uma favela lamacenta exibe seres humanos que vivem do lixo, aidéticos que morrem à míngua, solitários em suas casas de um cômodo só, sem luz, sem água e sem leito. De qualquer maneira, o pequeno núcleo exemplar começa a suscitar o interesse de moradores de outras áreas que já começam a construir suas casinhas precárias, seus barracos nas encostas do morro, alheios ao espírito comunitário que suscitou a experiência. Os pioneiros de Rancho Fundo percebem isso e revelam apreensão em suas entrevistas. Em Chatuba, como em Rancho Fundo e em toda a Baixada, projetos de melhoramentos circunscritos suscitarão necessariamente migrações internas. Os problemas sociais da Baixada tornaram-se crônicos e já não comportam paliativos ou exercícios experimentais. Técnicos envolvidos em tais projetos tendem a encarecê-los porque, mesmo quando parciais e de reduzidíssimas conseqüências, demandam um trabalho insano e competência extraordinária para que venham à luz.

Criticá-los é injusto e perverso. Portanto, a limitação aqui insinuada não os atinge. Abatese sobre um quadro histórico para cujo enfrentamento torna-se necessário assumir responsabilidades por omissões de sessenta anos que, pela sua natureza, não prescrevem. Afirmar perante o cidadão que o elegeu que o problema se arrasta há décadas e "ele” não pode resolver em um mandato pode ter o sentido pragmático de instalar no horizonte do cenário que a frase ajuda a construir a possibilidade de "ele” pleiteie um novo mandato. Mas, o sentido relevante é o da demissão dos compromissos do Estado, assumidos quando se assume um mandato. As descontinuidades impostas pela partidarização das responsabilidades funcionam como um complicador dessas relações complexas (e complicadas) que são as relações do Estado com suas periferias. Ademais, a consideração torna-se descabida junto a populações que aspiram, sobretudo, a resolverem seus problemas históricos e, secundariamente, os contraídos nos últimos três anos. Fez-se no início deste texto referência a mudança de governo e sua compulsão à descontinuidade e ruptura. Isto se observa em planos vários, municipais, estaduais e federais. Quem assume um cargo público, assume um duplo compromisso, um com suas promessas de palanque, 
outro com os desmandos do passado. Parece que meus informantes começam a entender isso. Não teria meios de quantificar a extensão de tal percepção entre a população da Baixada. Mas, uma propriedade fica clara: os segmentos que o percebem andam bastante agitados e falastrões. Costumam contar com um público silencioso, mas atento. A possibilidade de um crescente compartilhamento de tais expectativas parece bastante provável. O contexto, pelo menos, vem colaborando para isso de forma contundente.

\section{Bibliografia}

ABREU, Maurício. A evolução urbana do Rio de Janeiro. Rio de Janeiro: IPLANRIO/ Zahar, 1988.

ALVES, José Cláudio Souza. Baixada Fluminense: a violência na construção do poder. São Paulo: USP/FFLCH. 1998 (tese de doutoramento).

ALVES, José Cláudio Souza. "Religião, violência e poder político numa favela da Baixada Fluminense”. Trabalho apresentado no GT Religião e Sociedade. XXVI Encontro Anual da Associação Nacional de Pós-Graduação e Pesquisa em Ciências Sociais, 21-25 de outubro de 2003.

BELOCH, Israel. Capa preta e lurdinha. Tenório Cavalcanti e o povo da Baixada. Rio de Janeiro: Record, 1986.

BLUMER, Herbert. El interaccionismo simbólico. Buenos Aires:

DINIZ, Eli. Voto e máquina política: patronagem e clientelismo no Rio de Janeiro. Rio de Janeiro: Paz e Terra, 1982.

ENNE, Ana. "Lugar meu amigo, é minha Baixada”: Memória, Representações Sociais e Identidades. Rio de Janeiro: PPGAS/MN/UFRJ, 2002 (tese de doutoramento).

GOFFMAN, Erving. Frame analysis. Boston: Northeastern University Press, 1986.

GOFFMAN, Erving. Os momentos e seus homens. Lisboa: Relógio D’Água: 1999.

Governo do Estado do Rio de Janeiro. Imprensa Oficial. "Municípios e Topônimos Fluminenses: Histórico e Memória". 
GRAMADO, Paulo. Zito. Rompendo barrerias com justiça e trabalho. Rio de Janeiro: Liberato, 1999.

Governo do Estado do Rio de Janeiro\Secretaria de Planejamento\CIDE. Diagnóstico Institucional e de Sustentabilidade do Programa, Social e das Condições AmbientaisPNB-01.01. 00-01001-RE

Atualização dos Diagnósticos das Condições Sócio-Ambientais e dos Aspectos Institucionais e de Sustentabilidade do Programa do Bairro da Chatuba - PNB20.03.00-04001-PL

Atualização dos Diagnósticos das Condições Sócio-Ambientais e dos Aspectos Institucionais e de Sustentabilidade do Programa do Bairro Santa Terezinha PNB-20.04.00-04001-PL 96/2000

Atualização dos Diagnósticos das Condições Sócio-Ambientais e dos Aspectos Institucionais e de Sustentabilidade do Programa do Bairro Jardim Metrópole PNB-27.03.00-04001-PL 96/2000

Atualização dos Diagnósticos das Condições Sócio-Ambientais e dos Aspectos Institucionais e de Sustentabilidade do Programa do Bairro Coelho da Rocha PNB-27.01.00-04001-PL 97/2000

Atualização dos Diagnósticos das Condições Sócio-Ambientais e dos Aspectos Institucionais e de Sustentabilidade do Programa do Bairro Jardim Leal / Centenário - PNB-12.05.00-04001-PL 97/2000

Atualização dos Diagnósticos das Condições Sócio-Ambientais e dos Aspectos Institucionais e de Sustentabilidade do Programa do Bairro Olavo Bilac - PNB12.04.00-04001-PL 96/2000

Atualização dos Diagnósticos das Condições Sócio-Ambientais e dos Aspectos Institucionais e de Sustentabilidade do Programa do Bairro Lote XV - PNB11.01.00-04001-PL 96/2000

Atualização dos Diagnósticos das Condições Sócio-Ambientais e dos Aspectos Institucionais e de Sustentabilidade do Programa do Bairro Xavantes - PNB11.01.00-04001-PL 97/2000 
JOSEPH, Isaac. Erving Goffman et la microsociologie. Paris: Presses Universitaires de France, 1998.

OLIVEN, Ruben George. Urbanização e mudança social no Brasil. Petrópolis: Vozes, 1980. 